\title{
Study on reaction kinetics of single slime
}

\author{
Kun Zhou ${ }^{1, a}$, Wei Fu' ${ }^{1}$, Hongxi Xie ${ }^{1}$, Jihu Bao ${ }^{1}$, Yayun $\mathrm{Li}^{1}$, Lei Lu${ }^{1}$ and Yunlang Cheng ${ }^{1}$ \\ ${ }^{1}$ Hefei General Machinery Research Institute, Hefei, Anhui Province, 230031
}

\begin{abstract}
The study of the combustion characteristics of single slime fuels is the basis for achieving clean combustion of solid fuels. This paper uses a combination of experimental and theoretical analysis, combined with the Coats-Redfen integration method, to study the influence of ash content and heating rate on the kinetic parameters of coal slime, and solve the combustion kinetic parameters. The results show that under the same heating rate, the activation energy gradually increases. As the ash content of coal slime increases, the activity of the coal slime sample decreases, and the reaction activation energy gradually increases.
\end{abstract}

\section{INTRODUCTION}

Due to the different production areas, the various physical parameters (fixed carbon, volatile content, ash and calorific value) of solid fuels will have obvious differences. Therefore, many researchers focus their work on solid fuel thermal analysis on the effects of physical parameters on the combustion process, combustion characteristic parameters and kinetic parameters. Among them, the research on kinetic parameters has the most popular application prospects.

Ozbas et al. [1] used the Coats-Redfern integration method to calculate combustion kinetic parameters. Lu et al. [2] found that under the same heating rate, the activation energy of the pyrolysis reaction of the sample is positively correlated with the conversion rate. Liu et al. [3] found that the activation energy, pre-exponential factor, and reaction order of the four coal powders they studied all increased to varying degrees with the increase of oxygen concentration. Yu et al. [4] used differential scanning calorimetry (DSC) and other methods to study the effect of sample particle size on the industrial analysis and combustion characteristics of coal samples. Ozbas et al. [5] found that with the increase of heating rate, the burn-out temperature of raw coal and clean coal gradually increased, and the activation energy gradually decreased.

In this paper, the Coats-Redfen integral method is used to solve the kinetic parameters (activation energy and prefactor) of the studied coal slime samples; the influence of ash content and heating rate on kinetic parameters is studied.

\section{OVERVIEW OF SOLUTION METHODS AND TESTED FUELS}

At the beginning of the 20th century, Vallett proposed a kinetic equation for non-isothermal and heterogeneous reactions: $\frac{\mathrm{d} x}{\mathrm{~d} T}=\left(\frac{1}{\beta}\right) k(T) f(x)(1)$

In Eq. (1), $\beta$ is the heating rate and be calculated as shown in Eq. (2), $x$ is the conversion percentage.

$$
\beta=\mathrm{d} T / \mathrm{d} t(2)
$$

The rate constant-temperature relationship proposed by Arrhenius:

$$
k=A \exp (-E / R T)
$$

In Eq. (3), A refers to the prefactor; $E$ is the activation energy, $\mathrm{kJ} / \mathrm{mol}$; $\mathrm{R}$ is the molar gas constant, $8.314 \mathrm{~J} / \mathrm{mol}$; T is the thermodynamic temperature, K. Substituting the Arrhenius equation into the kinetic equation proposed by Vallett, the two most commonly used kinetic equations are obtained, such as Eq. (4-5).

\begin{tabular}{|c|c|c|}
\hline $\begin{array}{l}\text { Mechanism and } \\
\text { model }\end{array}$ & $f(x)$ & $g(x)$ \\
\hline $\begin{array}{l}1 \text {-first order } \\
\text { reaction }\end{array}$ & $1-x$ & $-\ln (1-x)$ \\
\hline $\begin{array}{l}2 \text {-second order } \\
\text { reaction }\end{array}$ & $(1-x)^{2}$ & $(1-x)^{-1}-1$ \\
\hline $\begin{array}{l}\text { 3-third order } \\
\text { reaction }\end{array}$ & $(1-x)^{3}$ & $1 / 2\left[(1-x)^{-2}-1\right]$ \\
\hline 4- shrink cylinder & $2(1-x)^{1 / 2}$ & $1-(1-x)^{1 / 2}$ \\
\hline 5- shrink globular & $3(1-x)^{1 / 3}$ & $1-(1-x)^{1 / 3}$ \\
\hline 6-parabola rule & $1 / 2 x^{-1}$ & $x^{2}$ \\
\hline 7-Valensi equation & {$[-\ln (1-x)]^{-1}$} & $(1-x) \ln (1-x)+x$ \\
\hline 8-Jander & $(1-x)^{1 / 2}\left[1-(1-x)^{1 / 2}\right]^{-1}$ & {$\left[1-(1-x)^{1 / 2}\right]^{2}$} \\
\hline 9-Jander equation & $3 / 2(1-x)^{2 / 3}\left[1-(1-x)^{1 / 3}\right]^{-1}$ & {$\left[1-(1-x)^{1 / 3}\right]^{2}$} \\
\hline 10-G-B equation & $3 / 2\left[(1-x)^{-1 / 3}-1\right]^{-1}$ & $1-2 x / 3-(1-x)^{2 / 3}$ \\
\hline 11-Z-L-T equation & $3 / 2(1-x)^{4 / 3}\left[(1-x)^{-1 / 3}-1\right]^{-1}$ & {$\left[(1-x)^{-1 / 3}-1\right]^{2}$} \\
\hline $\begin{array}{l}\text { 12-Avrami- } \\
\text { Erofeev }\end{array}$ & $1 / 2(1-x)[-\ln (1-x)]^{-1}$ & {$[-\ln (1-x)]^{2}$} \\
\hline
\end{tabular}

Table 1. Reaction mechanisms commonly used in solid-state

Differential formula:

$\frac{\mathrm{d} x}{\mathrm{~d} T}=\left(\frac{1}{\beta}\right) A \exp \left(-\frac{E}{R T}\right) f(x)$

Integral formula:

$$
G(x)=\int_{0}^{x} \frac{\mathrm{d} T}{f(x)}=\int_{T_{0}}^{T}(A / \beta) \exp (-E / R T) \mathrm{d} T
$$

\footnotetext{
a Corresponding author: zhoukun@gmpi.org.cn
} 
Table 2. Industrial analysis of four types of slime

\begin{tabular}{c|ccccc}
\hline \multirow{2}{*}{ Sample } & \multicolumn{5}{c}{ Industrial analysis (air dry basis) } \\
\cline { 2 - 6 } & $\begin{array}{c}\text { Fixed } \\
\text { carbon } \\
(\%)\end{array}$ & $\begin{array}{c}\text { Volatile } \\
\text { content } \\
(\%)\end{array}$ & $\begin{array}{c}\text { Water } \\
(\%)\end{array}$ & $\begin{array}{c}\text { Ash } \\
(\%)\end{array}$ & $\begin{array}{c}\text { Low } \\
\text { calorific } \\
\text { value } \\
(\mathrm{MJ} / \mathrm{kg})\end{array}$ \\
\hline 45A & 39.56 & 14.31 & 0.7 & 45.43 & 16.5 \\
$50 \mathrm{~A}$ & 30.61 & 16.73 & 2.45 & 50.21 & 14.2 \\
$55 \mathrm{~A}$ & 31.92 & 12.18 & 0.76 & 55.14 & 12.3 \\
\hline $65 \mathrm{~A}$ & 24.71 & 9.47 & 0.59 & 65.11 & 9.56 \\
\hline
\end{tabular}

$x$ is the conversion percentage, that is, the weight loss rate of the sample at a certain moment, as shown in Eq. (6). $m_{0}$ is the mass of the sample at the beginning of the reaction, $m$ is the mass of the sample at any time, and $m_{\infty}$ is the mass of the final residue.

$$
x=\frac{m_{0}-m}{m_{0}-m_{\infty}}
$$

Uses the Coats-Redfen integration method to integrate Eq. (5) and then get the corresponding basic equation:

$$
\ln \left(\frac{g(x)}{T^{2}}\right)=\ln \left(\frac{A R}{\beta E}(1-2 R T / E)\right)-E / R T
$$

In Eq. (7), $A$ is the pre-factor, $E$ is the apparent activation energy, $\mathrm{kJ} / \mathrm{mol} ; \mathrm{R}$ is the molar gas constant, $8.314 \mathrm{~J} / \mathrm{mol} ; \mathrm{T}$ is the reaction temperature, $\mathrm{K} ; \beta$ is the temperature rise rate, ${ }^{\circ} \mathrm{C} / \mathrm{min}$.

In the process of solving the kinetic parameters, the appropriate mechanism functions $\mathrm{f}(\mathrm{x})$ and $\mathrm{g}(\mathrm{x})$ must be selected first. According to the mechanism function and the selection method of mechanism function defined by scholars in related research fields, 12 mechanism functions were initially selected, as shown in Table 1 [6, 7]. According to the data obtained during the thermogravimetric experiment, the conversion percentage of the sample mass changes with temperature, combined with the above 12 mechanism functions, to solve for $\ln \left[\mathrm{g}(x) / \mathrm{T}^{2}\right]$.

Table 2 shows the industrial analysis of four types of slime.

\section{RESULTS AND DISCUSSION}

The linear correlation coefficient of the fitting straight line corresponding to the mechanism function 4 to 10 is relatively small. Here, only the linear correlation coefficients of the fitting straight line of the remaining five mechanism functions are listed, as shown in Table 3 , and the mechanism function 11 is found. That is, the Z-L-T equation has the largest linear correlation coefficient $\mathrm{R}^{2}$ of the linear fitting line, indicating the best degree of linear fitting. Therefore, when calculating the kinetic parameters of coal slime samples with different ash content under different heating rates, the Z-L-T equation is chosen as the

\begin{tabular}{|c|c|c|c|c|c|c|}
\hline \multirow{2}{*}{ Heating rate } & \multirow{2}{*}{ Sample } & \multicolumn{5}{|c|}{$\mathrm{R}^{2}$} \\
\hline & & 1 & 2 & 3 & 11 & 12 \\
\hline \multirow{4}{*}{20} & $45 \mathrm{~A}$ & 0.96387 & 0.98872 & 0.98586 & 0.9973 & 0.96942 \\
\hline & $50 \mathrm{~A}$ & 0.95054 & 0.98206 & 0.98411 & 0.99359 & 0.96007 \\
\hline & $55 \mathrm{~A}$ & 0.95093 & 0.98268 & 0.99122 & 0.99359 & 0.95984 \\
\hline & $65 \mathrm{~A}$ & 0.90869 & 0.95629 & 0.99051 & 0.99292 & 0.92548 \\
\hline \multirow{4}{*}{30} & $45 \mathrm{~A}$ & 0.9941 & 0.99109 & 0.96606 & 0.99956 & 0.99508 \\
\hline & $50 \mathrm{~A}$ & 0.97959 & 0.99359 & 0.97091 & 0.99615 & 0.9835 \\
\hline & $55 \mathrm{~A}$ & 0.97122 & 0.99166 & 0.986 & 0.99906 & 0.97578 \\
\hline & $65 \mathrm{~A}$ & 0.94368 & 0.97502 & 0.98921 & 0.99056 & 0.95375 \\
\hline \multirow{4}{*}{50} & $45 \mathrm{~A}$ & 0.99228 & 0.98726 & 0.95654 & 0.99965 & 0.99368 \\
\hline & $50 \mathrm{~A}$ & 0.99596 & 0.98104 & 0.9441 & 0.99944 & 0.99695 \\
\hline & $55 \mathrm{~A}$ & 0.99502 & 0.98201 & 0.94575 & 0.99951 & 0.99619 \\
\hline & $65 \mathrm{~A}$ & 0.9948 & 0.97145 & 0.92899 & 0.99753 & 0.99315 \\
\hline
\end{tabular}
mechanism function.
According to the Z-L-T equation, $\ln \left[\mathrm{g}(x) / \mathrm{T}^{2}\right]$ is solved and is ploted versus $1 / \mathrm{T}$, and linear regression on the curve is also performed. According to the slope and intercept of the obtained straight line, the activation energy $\mathrm{E}$ and the pre-exponential factor A are obtained. The calculation results are shown in Table 4. 
Table 4. Coats-Redfen integral method calculation result with Z-L-T function

\begin{tabular}{|c|c|c|c|c|}
\hline Heating rate & Sample & $\mathrm{R}^{2}$ & $\mathrm{E} /(\mathrm{kJ} / \mathrm{mol})$ & $\mathrm{A} /(\min )^{-1}$ \\
\hline \multirow{4}{*}{20} & $45 \mathrm{~A}$ & 0.9973 & 245.38 & $2.2 \mathrm{E}+11$ \\
\hline & $50 \mathrm{~A}$ & 0.99359 & 254.3 & $2.5 \mathrm{E}+11$ \\
\hline & $55 \mathrm{~A}$ & 0.99359 & 250.35 & $3.96 \mathrm{E}+10$ \\
\hline & $65 \mathrm{~A}$ & 0.99292 & 265.27 & $1.64 \mathrm{E}+08$ \\
\hline \multirow{4}{*}{30} & $45 \mathrm{~A}$ & 0.99956 & 213.5 & $1.19 \mathrm{E}+9$ \\
\hline & $50 \mathrm{~A}$ & 0.99615 & 205.46 & $1.25 \mathrm{E}+8$ \\
\hline & 554 & 0.99906 & 207.57 & $1.92 \mathrm{E}+8$ \\
\hline & $65 \mathrm{~A}$ & 0.99056 & 244.14 & $4.53 \mathrm{E}+10$ \\
\hline \multirow{4}{*}{50} & $45 \mathrm{~A}$ & 0.99965 & 212.3 & $2.75 \mathrm{E}+8$ \\
\hline & $50 \mathrm{~A}$ & 0.99944 & 194.97 & $1.95 \mathrm{E}+8$ \\
\hline & $55 \mathrm{~A}$ & 0.99951 & 210.4 & $0.92 \mathrm{E}+9$ \\
\hline & & 0.99753 & 220.56 & $2.27 \mathrm{E}+8$ \\
\hline
\end{tabular}

As shown in Figure 1, as the heating rate increases, the activation energy of coal slime samples with the same ash content will gradually decrease. This shows that the increase in the heating rate increases the activity of the slime, thereby reducing the energy required for the slime reaction, resulting in easier reaction. The heating rate of the thermal analytical balance increases, and the heating rate of the slime sample increases. The increase in the heating rate of coal slime accelerates the precipitation rate of volatile matter and increases the amount of volatile matter precipitated, resulting in more porous structures in the slime particles. The appearance of the porous structure increases the surface area where the fuel and oxygen molecules contact, and finally promotes the ignition and combustion reaction of coal slime. When the heating rate is constant, with the increase of ash content, the activation energy of coal slime samples shows an overall upward trend. This shows that as the ash content increases, the reaction activity of coal slime shows a decreasing trend, leading to a gradual increase in the energy required for the reaction. When the heating rate is $20^{\circ} \mathrm{C} / \mathrm{min}$, the activation energy of $45 \mathrm{~A}$ slime is the lowest, which is $245.38 \mathrm{~kJ} / \mathrm{mol}$. When the heating rate is $30^{\circ} \mathrm{C} / \mathrm{min}$ and $50^{\circ} \mathrm{C} / \mathrm{min}$, the activation energy of $50 \mathrm{~A}$ slime is the lowest, which are $205.46 \mathrm{~kJ} / \mathrm{mol}$ and $194.97 \mathrm{~kJ} / \mathrm{mol}$, respectively.

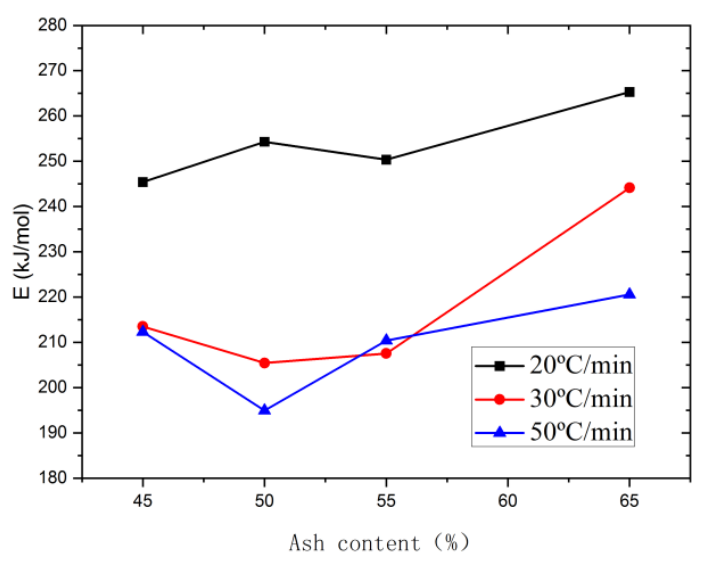

Figure 1. Activation energy of coal slime samples with ash content and heating rate

\section{CONCLUSION}

The heating rate and the ash content of the slime have no influence on the selection of the most suitable mechanism function. The best mechanism function is the Z-L-T equation. As the ash content of coal slime increases, the activity of the coal slime sample decreases, and the reaction activation energy gradually increases. At a higher heating rate, 50A coal slime has the lowest activation energy and the best activity. For the same kind of slime, the increase in the heating rate increases the heating rate of the slime, increases the activity of the slime reaction, and reduces the reaction activation energy.

\section{Acknowledgments}

Thanks for the support from Hefei General Machinery Research Institute and University of Science and Technology of China. 


\section{References}

1. Ozbas K, Kök M, Hicyilmaz C. Comparative kinetic analysis of raw and cleaned coals[J]. Journal of thermal analysis and calorimetry, 2002, 69(2): 541549.

2. Shuai L , Guo-Jun L, Xu-Guang J, et al. Pyrolysis/combustion characteristics and kinetic analysis of Indonesia lignite sludge $[\mathrm{J}]$. Journal of China Coal Society, 2014.

3. Liu R, An E, Liu Z . Kinetic Parameters of Oxy-coal Combustion in Low Oxygen Concentration with Thermogravimetry[J]. Journal of Tongji University(Natural ence), 2014, 42(9):1415-1420.

4. Yu D, Xu M, Sui J, et al. Effect of coal particle size on the proximate composition and combustion properties[J]. Thermochimica Acta, 2005, 439(1-2): 103-109.

5. ÖZBAS K E, KÖK M V. Effect of heating rate on thermal properties and kinetics of raw and cleaned coal samples[J]. Energy Sources, 2003, 25(1): 33-42.

6. Aboulkas A, El harfi K, El Bouadili A. Thermal degradation behaviors of polyethylene and polypropylene. Part I: Pyrolysis kinetics and mechanisms $[\mathrm{J}]$. Energy Conversion and Management 2010;51:1363-9.

7. Khawam A, Flanagan DR. Role of isoconversional methods in varying activation energies of solid-state kinetics[J]. Thermochimica Acta 2005;436:101-12. 